\section{Response to: 'Unending story of the indirect immunofluorescence assay on HEp-2 cells: old problems and new solutions?' by Meroni et al}

We would like to thank Professor Meroni and colleagues for their comments ${ }^{1}$ regarding our paper $^{2}$ on testing for antinuclear antibodies (ANAs) in patients with systemic lupus erythematosus (SLE) and the very thoughtful discussion of the approaches for serological determinations. This letter provides a further perspective on ANA assays that were also discussed in a letter to this journal by Dr M Mahler. ${ }^{3}$ With respect to approaches to serological testing beyond immunofluorescence assays (IFA), we fully agree that solid phase assays (SPA) can provide a useful adjunctive approach and, indeed, we provided data on an ANA ELISA in our paper. In our study, the SPA kit that we assessed did not perform better than the IFA tests $111.7 \%$ ANA negative for the SPA compared with $4.9 \%-22.3 \%$ negative for IFA assays).

While ANA assays have undergone extensive investigation, one of the current challenges relates to the setting of clinical trials and the high screen failure rate of patients who have an established diagnosis of SLE but are ANA-negative at screening despite a positive ANA in the past. Screening for trial eligibility involves different considerations from those used for routine care and, indeed, may necessitate different assays. Importantly, since products for the treatment of SLE can be approved for 'active, autoantibody positive disease', the assays used for serological assessment are key and therefore should be rigorously evaluated for use as a 'theranostic' or companion diagnostic. Such an evaluation requires different methodology from what is currently used to evaluate a kit or assay to assess the presence of an ANA in a broad population of patients with a systemic autoimmune rheumatic disease. In his letter, Dr Mahler ${ }^{3}$ discussed the differences between companion and complementary diagnostics. The use of the different ANA kits for screening for trial eligibility has not yet been the subject of such an evaluation, adding uncertainty to the field. We discussed these issues in a previous publication. ${ }^{4}$

To move the field forward, we would suggest greater clarity in the goal of ANA testing in the trial setting. Is such testing to confirm a diagnosis of SLE or is it to subset patients on the basis of disease activity, suspected mechanistic underpinning of the disease and/or the likelihood of treatment response? In this regard, while anti-DNA has had extensive use to assess disease activity and is a component of the Systemic Lupus Erythematosus (SLEDAI), for example, testing for either ANA or antibodies to RNA-binding proteins (ie, Sm, RNP, Ro and La) has not been considered useful to assess disease activity. ${ }^{5}$ We, therefore, believe that regulatory agencies in concert with investigators should directly address the issue of ANA testing to determine trial eligibility and provide guidance on the methodology that is the most informative and reliable in this specific setting. This methodology could involve more than one IFA kit or the combination of an IFA and SPA; for example, in our study, only one patient showed ANA negativity in all three IFA assays. Standardisation is also important to allow comparison of studies.

We agree that confusion currently surrounds the issue of ANA testing in clinical trials and hope that our paper begins the process to come to a resolution. In view of the pipeline of new agents that can be explored as novel therapeutics for SLE, such a resolution should be a top priority to advance the testing of new treatments and the addition of effective new agents to the armamentarium.

\section{David S Pisetsky, ${ }^{1}$ Diane M Spencer, ${ }^{1}$ Peter E Lipsky, ${ }^{2}$ Brad H Rovin ${ }^{3}$}

${ }^{1}$ Department of Medicine and Immunology, Duke University Medical Center and Medical Research Service, VA Medical Center, Durham, North Carolina, USA

${ }^{2}$ RILITE Research Institute, Charlottesville, Virginia, USA

${ }^{3}$ Division of Nephrology, Ohio State University Wexner Medical Center, Columbus, Ohio, USA

Correspondence to Dr David S Pisetsky, Department of Medicine and Immunology, Duke University Medical Center, Durham, NC 27705, USA; david.pisetsky@duke.edu Handling editor Josef S Smolen

Funding The authors have not declared a specific grant for this research from any funding agency in the public, commercial or not-for-profit sectors.

Competing interests None declared.

Patient consent Not required.

Provenance and peer review Commissioned; internally peer reviewed.

(c) Article author(s) (or their employer(s) unless otherwise stated in the text of the article) 2019. All rights reserved. No commercial use is permitted unless otherwise expressly granted.

\section{Check for updates}

To cite Pisetsky DS, Spencer DM, Lipsky PE, et al. Ann Rheum Dis 2019;78:e47.

Received 11 April 2018

Revised 18 April 2018

Accepted 19 April 2018

Published Online First 28 April 2018

\section{Linked}

http://dx.doi.org/10.1136/annrheumdis-2018-213440

Ann Rheum Dis 2019;78:e47. doi:10.1136/annrheumdis-2018-213537

\section{REFERENCES}

1 Meroni PL, Chan EK, Damoiseaux J, et al. Unending story of the indirect immunofluorescence assay on HEp-2 cells: old problems and new solutions? Ann Rheum Dis 2019:78:e46.

2 Pisetsky DS, Spencer DM, Lipsky PE, et al. Assay variation in the detection of antinuclear antibodies in the sera of patients with established SLE. Ann Rheum Dis 2018;77:911-3

3 Mahler M. Lack of standardisation of ANA and implications for drug development and precision medicine. Ann Rheum Dis 2019;78:e33.

4 Pisetsky DS, Rovin BH, Lipsky PE. New perspectives in rheumatology: biomarkers as entry criteria for clinical trials of new therapies for systemic lupus erythematosus: the example of antinuclear antibodies and anti-DNA. Arthritis Rheumatol 2017;69:487-93.

$5 \mathrm{McC}$ arty GA, Rice JR, Bembe ML, et al. Independent expression of autoantibodies in systemic lupus erythematosus. J Rheumatol 1982;9:691-5. 